\title{
Experimental Study on Forced-Air Precooling of Dutch Cucumbers
}

\author{
Jingying Tan, Shi Li, and Qing Wang \\ School of Mechanical Engineering, Hunan Institute of Science and Technology, Yueyang, \\ Hunan Province, China 41400 \\ \{jingyingtan, wqwyy\}@163.com, 7750496@qq.com
}

\begin{abstract}
Experiments about the forced-air precooling of cucumbers were carried out under different operation parameters. The results show that the relation between cooling rate and air velocity can be given by power function. The linear relationship between the initial temperature of cold air and cucumbers and the final temperature of cucumbers is gained. Temperature gradient exists in different radius position in the same cross section. But the temperature gradient is not significant for the beginning and the final during the procooling process.
\end{abstract}

Keywords: Forced-air precooling, air velocity, initial temperature, temperature gradient.

\section{Introduction}

The precooling means that the tempreature is quickly decreased from the room temperature to the storage temperature. The precooling process is an important technological part for the food storage. The shelf life of the fruit-vegetable can be delayed significantly and the freshness and the nutritional ingredient can be kept better after precooling. There are several types for precooling, such as vacuum precooling, forced-air precooling, water precooling, water-air precooling. Several factors, such as precooling cost, precooling time, and the conditions of the cooling process, must be considered in the choice of the precooling types [1-2]. The parameters of the precooling process can be predicted accurately according to the experimental data of precooling, experimental formula, and some charts. Ibrahim Dincer researched the precooling process of grape monocase by experiments [3]. Vigneault researched the ventilation resistance of the precooling [4]. Some researches did some experiments about the differential pressure precooling for the opening packing container [5-7]. The experiements were done in the long and narrow duct.

The previous researches focused on the experiments and there were some differences comparing with the practical precooling production. The forced-air precooling, the best suitable types of the precooling for my country, is studied for the Dutch cucumbers in this paper. The effect of the precooling parameters during the precooling process is given. 


\section{Materials and Methods}

\subsection{Materials}

The column Dutch cucumbers gained from the demonstration base of Country Farming Production in Tianjin were used in the experiment. The sizes of the cucumbers are uniform, diameter $25 \mathrm{~mm}$, and there are no plant diseases and insect pests and mechanical damnification.

\subsection{Experimental Conditions}

The experiments are conducted in the fruit-vegetable pre-refrigeratory and the conditions are follows:

(1) air velocity: $0.5 \mathrm{~m} / \mathrm{s}, 1.0 \mathrm{~m} / \mathrm{s}, 1.25 \mathrm{~m} / \mathrm{s}, 1.5 \mathrm{~m} / \mathrm{s}, 1.75 \mathrm{~m} / \mathrm{s}$, and $2 \mathrm{~m} / \mathrm{s}$.

(2) initial temperature for cold air: $2^{\circ} \mathrm{C}, 3^{\circ} \mathrm{C}, 4^{\circ} \mathrm{C}, 5^{\circ} \mathrm{C}$, and $6^{\circ} \mathrm{C}$.

(3) initial temperature for cucumber: $18^{\circ} \mathrm{C}, 19^{\circ} \mathrm{C}, 20^{\circ} \mathrm{C}, 21^{\circ} \mathrm{C}, 22^{\circ} \mathrm{C}, 23^{\circ} \mathrm{C}, 24^{\circ} \mathrm{C}$, $25^{\circ} \mathrm{C}, 26^{\circ} \mathrm{C}, 27^{\circ} \mathrm{C}$, and $28^{\circ} \mathrm{C}$.

4) measuring position of the cucumber: center section, $1 / 2$ radius, $3 / 4$ radius, and surface.

\subsection{Data Acquisition System}

(1) temperature acquisition system

The armoured thermocouple, WRNK-111, $\varphi 1 \times 1000 \mathrm{~ms}$, leading wire $5 \mathrm{~m}$, is used to measure the temperature. The standard mercury filled thermometer is used to calibrate, $\pm 0.1^{\circ} \mathrm{C}$ for the measurement accuracy.

(2) humidity acquisition system

EE21-FT6A23CA0170 system is used to defect the humidity real-time.

(3) air velocity acquisition system

The sensor of EE65-VB5 ELEKTRONIK is chosen.

The data of the temperature, humidity, and the air velocity is collected by computer, 30s for the minimum collection interval. The interval of $1 \mathrm{~min}$ is chosen for the data acquisition in the experiment.

The air velocity sensor, the temperature sensor, and the humidity sensor of SwemaAir300 are used for the experiment.

\section{Results and Discussions}

\subsection{The Effect of the Air Velocity on the Falling Temperature of the Center}

The falling temperature curves, the initial temperature of cold air $4^{\circ} \mathrm{C}$ and cucumber $25^{\circ} \mathrm{C}$, are shown in Fig. 1. 


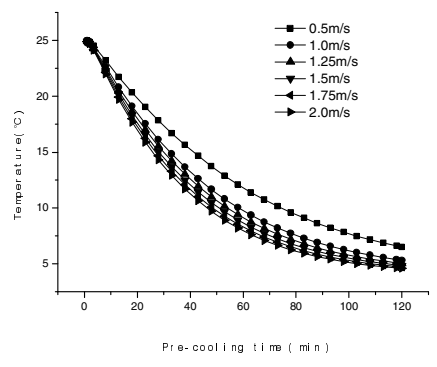

Fig. 1. The effect of the air velocity during the precooling process

It can be seen that the falling temperature curves are similar under air velocities. But the falling temperature effect is not proportional to the air velocity. The better precooling effect can not be gained by increasing air velocity, but the cost will quickly increase, especially more than $1.5 \mathrm{~m} / \mathrm{s}$. So it can be concluded that the air velocity $1.5 \mathrm{~m} / \mathrm{s}$ is suitable.

The falling temperature equation for different air velocities is given by fitting the falling temperature curves.

$$
T=T_{0}+A_{0} e^{-R_{0} t}
$$

The parameter T0, R0, and A0 are shown in Table 1.

Equation 1 can be rewritten

$$
\frac{T-T_{0}}{T_{i}-T_{0}}=e^{-R_{0} t}
$$

Where $\mathrm{T}$, center temperature at any time; T0, initial temperaure of center temperaure; $\mathrm{Ti}$, cold air temperature; $\mathrm{A} 0=\mathrm{Ti}-\mathrm{T} 0$, fitting value; $\mathrm{R} 0$, cooling rate in center.

The cooling rate will increase with the air velocity increasing and the relationship between them can be discribed by the power function according to table 1 and figure. 2. Equation 3 is given.

$$
R_{0}=0.2207 u^{0.35352}
$$


Table 1. Fitting results for different air velocities

\begin{tabular}{|c|c|c|c|c|c|c|}
\hline & & & A0 & R0 & T0 & $\begin{array}{c}\text { Correlation } \\
\text { coerricent R2 }\end{array}$ \\
\hline \multirow{12}{*}{ 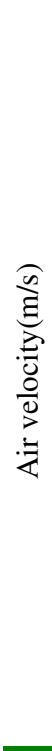 } & & Fitting value & 21.8373 & 0.01717 & 4 & \\
\hline & 0.5 & $\begin{array}{l}\text { Standard } \\
\text { deviation }\end{array}$ & \pm 0.11115 & \pm 0.00017 & \pm 0 & 0.99853 \\
\hline & & Fitting value & 21.96015 & 0.02215 & 4 & \\
\hline & 1.0 & $\begin{array}{l}\text { Standard } \\
\text { deviation }\end{array}$ & \pm 0.11982 & \pm 0.00022 & \pm 0 & 0.99868 \\
\hline & & Fitting value & 21.99931 & 0.02396 & 4 & \\
\hline & 1.25 & $\begin{array}{l}\text { Standard } \\
\text { deviation }\end{array}$ & \pm 0.1211 & \pm 0.00024 & \pm 0 & 0.99874 \\
\hline & & Fitting value & 22.03124 & 0.02551 & 4 & \\
\hline & 1.5 & $\begin{array}{l}\text { Standard } \\
\text { deviation }\end{array}$ & \pm 0.12169 & \pm 0.00026 & \pm 0 & 0.99879 \\
\hline & & Fitting value & 22.03496 & 0.02557 & 4 & \\
\hline & 1.75 & $\begin{array}{l}\text { Standard } \\
\text { deviation }\end{array}$ & \pm 0.12207 & \pm 0.00026 & \pm 0 & 0.99879 \\
\hline & & Fitting value & 22.08216 & 0.02809 & 4 & \\
\hline & 2.0 & $\begin{array}{l}\text { Standard } \\
\text { deviation }\end{array}$ & \pm 0.12196 & \pm 0.00029 & \pm 0 & 0.99887 \\
\hline
\end{tabular}

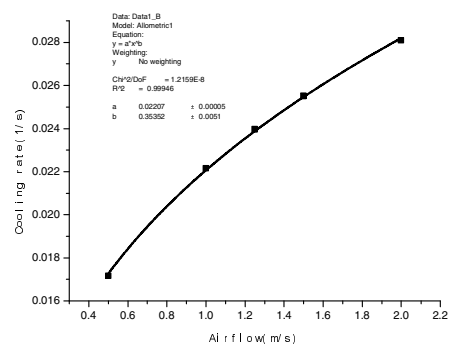

Fig. 2. Fitting curves between the cooling rate and the air velocity in the center

\subsection{The Effect of the Initial Temperature of Cold Air during the Precooling Process}

The results for the effect of the initial temperature of cold air during the precooling process is shown in Fig. 3, air velocity $1.5 \mathrm{~m} / \mathrm{s}$ and the initial temperature of cucumber $25^{\circ} \mathrm{C}$.

It can be seen that the temperature decreases quickly when the lower initial temperature and the lower final temperature will be gained after precooling for two hours. The temperature curves between the initial temperature of cold air and the final temperature of cucumber are given in Fig. 4 and the linear relationship is given. 


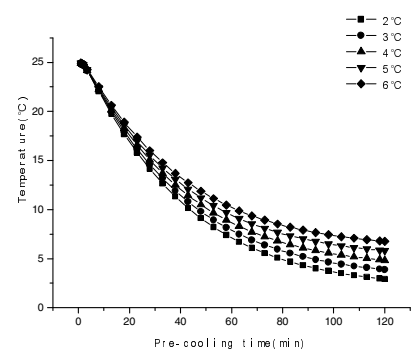

Fig. 3. The effect of the initial temperature of cold air during the precooling process in center

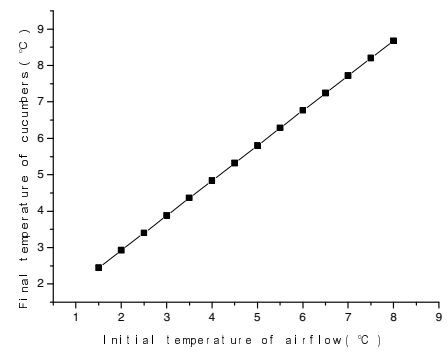

Fig. 4. The relationship between the initial temperature of cold air and the final temperature of cucumber in center

\subsection{The Effect of the Initial Temperature on the Final Temperature for the Cucumber}

The precooling curves of different initial temperature are given in Fig. 5, the initial temperature of the cold air $4^{\circ} \mathrm{C}$ and air velocity $1.5 \mathrm{~m} / \mathrm{s}$.

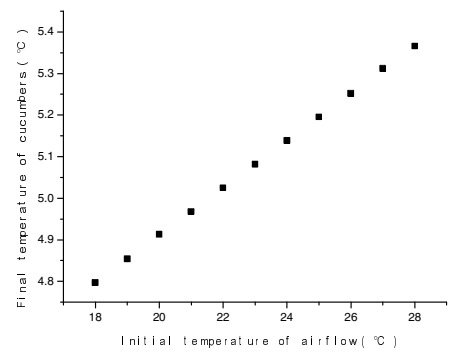

Fig. 5. The relationship between the initial temperatures and the final temperature

The linear relationship between the initial temperatures of airflow and final temperature of cucumbers is gained and it is similar to the previous results. 


\subsection{The Temperature Changes in Different Section for the Whole Precooling Process}

The temperature change curves for different sections, center, $1 / 2$ radius, $1 / 4$ radius, and surface, are given, air velocity $1.5 \mathrm{~m} / \mathrm{s}$, initial temperature for cucumber $25^{\circ} \mathrm{C}$, initial temperature for cold air $4^{\circ} \mathrm{C}$.

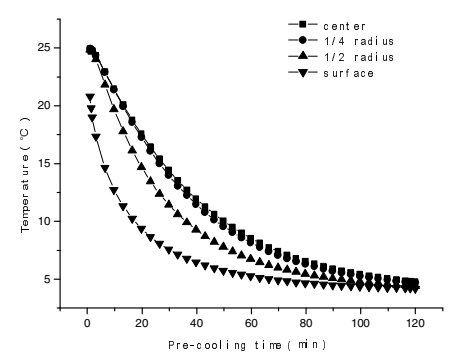

Fig. 6. The temperature changes in different section during the precooling process

It can be concluded that there is temperature gradient in different radius of the same cross section during the precooling process. The high cooling rate near the outside of the cucumber is gained due to the small resistance. The final temperature of the cucumber is close to the initial temperature of cold air $4^{\circ} \mathrm{C}$ after the long precooling process.

\section{Conclusions}

It can be concluded from the forced-air precooling experiments for the cucumbers.

(1) Cooling rate increases with the increase in air velocity and the power function relationship between them is gained. air velocity $1.5 \mathrm{~m} / \mathrm{s}$ is best suitable for the precooling.

(2) There is the linear relationship between the initial temperature of the cold air and the cucumber and the final temperature of cucumber. The better cooling effect can be gained if the lower temperature of cold air is used, but the damage should be prevented when lower temperaure. The operation efficiency can be impoved when the fruit-vegetables are picked not at noon but in dusk or in morning.

(3) There is temperature gradient in different radius of the same cross section. Sometimes the temperature gradient is significant during the precooling process due to the inside resistance of the cucumbers.

Acknowledgements. The authors are grateful for A Project Supported by Scientific Research Fund of Hunan Provincial Education Department (10B043), A Project Supported by Scientific Research Fund of department of science and technology Hunan Province P. R. China (2009GK3044) and A Project Supported by Scientific Research Fund of Hunan Institute of Science and Technology(2010Y38). 


\section{References}

1. Jin, D., Tan, J.Y., Wang, Q.: Study on Refrigeratory Compressor with Frequency Conversion and its Economical Efficiency. In: International Conference on Computer and Computing Technologies in Agriculture, Nanchang, pp. 445-451 (2010)

2. Tan, J.Y., Jin, D., Wang, Q.: Study on the forced-air precooling process of torispherecal fruits and vegetables in cooling bed. Intillegent Automation \& Soft Cumputing 16(6), 1187-1195 (2010)

3. Ibrahim, D.: Air flow precooling of individual grapes. Journal of Food Engineering 26, 243-249 (1995)

4. Vigneault, C., Markarian, N.R., Silva, A., et al.: Pressure drop during forced-air ventilation of various shorticultural produce in containers with different opening configurations. Transactions of the ASAE 47(3), 807-814 (2004)

5. Yang, Z., Zhao, C.E., Wang, L.Y., et al.: Pressure Drop Characteristics in Forced-air Precooling of Longan Fruits. Transactions of the Chinese Society for Agricultural Machinery 38(1), 105-108 (2007)

6. Huang, J., Liu, J., Fang, Z.: Experimental study on pressure drop in pressure-difference precooling of cylinder fruits. Refrigeration and Air Conditioning 5(3), 61-65 (2005)

7. Wang, Q., Liu, F.Z., Lian, T.D.: Experimental study on parameters affecting grape pressure pre-cooling. Transactions of the Chinese Society of Agricultural Engineering 22(4), 212-215 (2006) 